with receptors coupled to $\mathrm{G}$ proteins.

From the reader's point of view, $R e$ ceptor has two irritating defects, both easy to fix. First, after listing the title and authors, each paper begins with a list of its contents, in outline form; this wasteful practice takes up space, tells us nothing we need to know and relegates the abstract of the paper onto a second page. Second, reviews are not identified as such in either the table of contents or elsewhere.

Henry R. Bourne is in the Departments of Pharmacology and Medicine and the Cardiovascular Research Institute, University of California, San Francisco, California 94143, USA.

\section{Sugar daddy}

\section{A. Rees}

Glycobiology. Editor-in-chief Gerald W. Hart. Oxford University Press. 6/yr. Europe $£ 150$, elsewhere $£ 250$ (institutional); Europe $£ 75$, elsewhere $\$ 125$ (personal).

JOURNALS dedicated to carbohydrate technology, especially starch and cellulose, and to carbohydrate reviews, have been well established for many years. Specialist journals for fundamental carbohydrate research are of a more recent inception, and the launch of the first of these in the mid-1960s was not without controversy. Most of us then working on carbohydrate problems had spent our entire careers in the field and could trace scientific lineages through distinguished and similarly specialized mentors, all the way back to the beginnings of the subject. I was in the camp opposing the journal on the grounds that intellectual inbreeding had gone too far and was leading to a degree of isolation that might be exacerbated by separate research publications. Better, we believed, to break out to mix with other research areas than to keep to home territory. Some of us published and presented research on polysaccharide structure and function alongside similar work on proteins and nucleic acids, with much benefit to our methods and insights. Others contributed through their work on carbohydrate synthesis and reaction mechanisms to the development of central concepts of organic natural products as a whole. In the light of subsequent experience, the issues were not really as black and white as they seemed and I think the specialist journals have brought more good than bad. But still, a balance has to be kept and it is reasonable to ask again, as we did before, whether any new field-specific journal looks like a venture to establish a sanctuary to which it would be too easy for intellectual introverts to retreat.

Setting prejudice aside to read Glycobiology itself and to peruse the membership of the editorial board, it seems that history has by now brought about a strange inversion. It is refreshing that Glycobiology is engaging so many scientists who have entered from successful backgrounds in other fields or who continue to work in parallel in other fields. In his inaugural leading article, Gerald Hart argues the need for a forum that such scientists would otherwise lack. Instead of there being the danger of tunnel vision, this community now feels the need for a sharper focus. Instead of there being a tradition that might threaten to stifle, the new research constituency now needs more communication among its members.

I do not think it can be denied that the concept of a focal journal does have some problems. No single journal can publish more than a small proportion of the good work in such a sprawling field as glycobiology. The early issues of this new journal are handsomely produced and present scientific work of high quality but, for example, the four representative issues I have been sent for review contain very little indeed on plant or prokaryotic systems. The main emphasis seems to be on mammalian glycoproteins in relation to biosynthesis, transport and recognition. Again, there seems to be a hint that, like the quest for the Holy Grail, we need an enterprise to search for a new biological function for carbohydrates that has eluded us thus far; is this really a good bet?

Overall, the journal has excellent features in the "Glyco-Forum", "MiniReview" and "Meeting Report" sections. These pull threads together with a carbohydrate orientation not found anywhere else in the scientific literature, and it is for this reason that the journal deserves to attract personal subscriptions. It should also become a core item for any serious library for biological research.

D. A. Rees is at the Medical Research Council, 20 Park Crescent, London W1N $4 A L, U K$.

\title{
Responses and reactions
}

\section{lan R. Phillips}

Pharmacogenetics. Editors J. R. Idle, F. J. Gonzalez and R. Kato. Chapman and Hall. 6/yr. US and Canada \$263, Europe $£ 142$, elsewhere $£ 152$ (institutional); US and Canada \$107, Europe £58, elsewhere $£ 58$ (personal).

PhARMACOGENETICs, the study of genetically determined variation in response to drugs, was established more than 30 years ago. The field was later extended, with the coining of the term 'ecogenetics', to cover all environmental and xenobiotic agents.

As is pointed out in a commentary in the first issue of Pharmacogenetics, the discipline is founded on discoveries that differences in response to three important drugs in use at the time, namely the anti-malarial primaquine, the local anaesthetic dibucaine and the antitubercular isoniazid, were due, respectively, to inherited variations in glucose6-phosphate dehydrogenase, pseudocholinesterase and acetyltransferase. It has since become clear that genetically determined variation in response to drugs is not confined to these classic textbook examples, but is an important factor underlying differential responses to many therapeutic drugs.

Pharmacogenetics, like many areas of biology, was revolutionized by the advent of molecular biology, which provided the probes and technology for determining the molecular genetics.

The journal publishes original research papers, leading articles, invited reviews and occasional invited commentaries, symposium proceedings and book reviews. There is also scope for scientific correspondence, although none appears in the early issues that I saw. The quality of production is excellent, as is speed of publication, most papers appearing two to four months after submission, some even in the same month as their acceptance. In the more recent issues a balance is beginning to be achieved between papers on molecular aspects and those of a more clinical or physiological nature. But of the 24 research papers in the first five issues, 19 were from members of the editorial board, and I detected a note of desperation in the editorial pleas for articles.

For me, the most successful feature of the journal is the series of excellent invited reviews, one in almost every issue. Covering topics from across the spectrum of pharmacogenetics, they are a valuable contribution to the field.

Pharmacogenetics is a useful addition to the literature. But I suspect that to succeed it will have to attract papers from a broader range of authors.

Ian R. Phillips is in the Department of Biochemistry, Queen Mary and Westfield College, University of London, Mile End Road, London E1 4NS, UK. 